\title{
ANALISIS FINANSIAL BEBERAPA METODA BUDIDAYA BANDENG DAN UDANG SECARA MONO DAN POLI KULTUR (Studi Kasus di Kecamatan Blanakan, Kabupaten Subang) Financial Analysis of Various Methods of Mono and
Poly Culture of the Milkfish and Shrimp
(Case Study in Blanakan Sub-District, Subang Regency)
}

\author{
"Admi Athirah, Tarunamulia, Ruzkiah Asaf dan Akhmad Mustafa \\ Balai Riset Perikanan Budidaya Air Payau dan Penyuluhan Perikanan (BRPBAP3) \\ Maros 90512; Jl. Makmur Daeng Sitakka No. 129 Maros 90512, Sulawesi Selatan \\ Telp : +62411371544 (371372), Fax : +62411371545 \\ Diterima tanggal: 24 Juli 2017 Diterima setelah perbaikan: 9 September 2017 \\ Disetujui terbit: 7 Desember 2017 \\ *email: m.athirah@gmail.com
}

\begin{abstract}
ABSTRAK
Bandeng dan udang merupakan komoditas utama dari hasil budidaya ikan di tambak, mempunyai potensi pengembangan yang cukup besar pada hampir semua lahan pantai di Indonesia. Penelitian ini bertujuan untuk mengkaji profil dan prospek budidaya ikan di tambak dengan menggunakan beberapa teknologi budidaya di Kabupaten Subang. Data primer dan sekunder digunakan dalam penelitian ini. Data primer diperoleh dari observasi terhadap kegiatan petambak di lokasi penelitian dan wawancara dengan bantuan kuesioner terstruktur pada responden petambak terpilih. Data sekunder diperoleh dari laporan hasil penelitian dan berbagai instansi yang terkait dengan penelitian. Analisis finansial usaha yang meliputi biaya total, pendapatan kotor, keuntungan operasional, keuntungan bersih, biaya produksi, RC Ratio, BEP dan masa pengembalian modal digunakan dalam penelitian ini. Ada 4 tipe teknologi budidaya ikan yang dipraktekkan oleh petambak di Kabupaten Subang, yaitu polikultur bandeng dengan udang windu, polikultur bandeng dengan udang vaname, monokultur bandeng dan teknologi intensif udang vannamei. Hasil penelitian menunjukkan bahwa profitabilitas usaha budidaya bandeng secara monokultur menduduki posisi tertinggi yang ditunjukkan oleh nilai RC-Rasio sebesar 2.33, kemudian usaha budidaya udang vannamei intensif dengan RC-Rasio sebesar 1.88, polikultur bandeng dengan udang windu dengan RC-Ratio sebesar 1.75 dan polikultur bandeng dengan udang vannamei dengan RC-Rasio sebesar 1.41. Hasil tersebut menunjukkan bahwa dengan kondisi lingkungan tambak yang ada pada saat penelitian dilakukan, usaha budidaya ikan bandeng secara monokultur lebih menguntungkan dibandingkan dengan ketiga teknologi budidaya ikan lainnya.
\end{abstract}

Kata Kunci: analisis finasial, teknologi budidaya ikan di tambak, ikan bandeng, udang, Kabupaten Subang

\begin{abstract}
Milkfish and shrimp are considered main commodities of pond fish culture and they have a great potential to be developed in almost all coastal area in Indonesia. This study aims to analyze pond fish culture profile and its prospect using several technologies of fish culture in Subang Regency. Primary and secondary data collection are applied in this study. Primary data were collected through observation and interview with selected fish farmer respondents using structured questionnaires. Secondary data were collected through research report and a number of related institutions. This study applied financial analysis method in terms of total cost, gross revenue, operational profit, net profit, cost of production, $R C$-Ratio, BEP and payback period. The research found that fish farmers in Subang Regency were practicing four different types of fish culture technologies, namely polyculture of milkfish with tiger prawn, polyculture of milkfish with vannamei shrimp, monoculture of milkfish, and intensive monoculture of vannamei shrimp. The result also indicated that the highest profit in terms of RC-Ratio of culture systems was monoculture of the milkfish (2.33), followed by the intensive monoculture of vannamei shrimp (1.88), polyculture of milkfish with tiger shrimp (1.75) and polyculture of milkfish with vannamei shrimp (1.41). It is concluded that monoculture of milkfish culture is more favorable compared with the other three fishpond culture technologies in the current environmental conditions.
\end{abstract}

Keywords: financial analysis, fish culture technology, brackishwater pond, milkfish, shrimp, Subang regency 


\section{PENDAHULUAN}

Pembangunan kelautan dan perikanan merupakan bagian integral dari pembangunan ekonomi secara keseluruhan dan harus menunjang terwujudnya perekonomian yang maju, efisien dan tangguh yang dicirikan oleh kemampuan dalam mensejahterakan pembudidaya tambak dan nelayan sekaligus meningkatkan kemandirian serta kemampuannya dalam mendorong sektor perikanan pada umumnya (Sapto, 2011). Salah satu upaya yang ditempuh untuk mewujudkan harapan tersebut adalah meningkatkan produksi dan produktivitas usaha perikanan untuk mencapai swasembada pangan berprotein hewani. Produksi perikanan dapat ditingkatkan melalui pengembangan kegiatan perikanan tangkap dan perikanan budidaya (akuakultur). Menurut Utojo et al. (2014), peningkatan produksi melalui pengembangan usaha perikanan budidaya ini diharapkan dapat memberikan kontribusi yang sangat nyata terhadap peningkatan pendapatan petambak, daerah, dan sebagai sumber devisa negara. Pada periode tahun 1970-1997, produksi udang dunia hasil budidaya meningkat $20-30 \%$ (700.000-1.000.000 ton) dengan kontribusi $24 \%$ dari total keuntungan perikanan budidaya (US\$ 6,6 trilyun) (Primavera, 1997).

Kabupaten Subang memiliki potensi lahan budidaya tambak seluas kurang lebih 10.000 ha yang tersebar di empat kecamatan yaitu Blanakan, Sukasari, Legon Kulon, dan Pusakanagara dengan panjang garis pantai $68 \mathrm{~km}$ (Taofiqurohman dan Ismail, 2012). Berbagai komoditas budidaya tambak yang telah dibudidayakan di Kabupaten Subang, termasuk di Kecamatan Blanakan adalah udang windu, udang vaname, dan ikan bandeng. Kecamatan Blanakan sudah dikenal dengan sentranya usaha budidaya tambak dengan teknologi ekstensif atau tradisional dan juga merupakan salah satu kawasan tambak yang menerapkan pola silvofishery atau wanamina.

Teknologi budidaya ikan di lahan tambak dapat dikatakan berhasil apabila teknologi tersebut secara biologis dapat diatasi, secara teknis dapat dilaksanakan, dan secara ekonomis dapat menguntungkan serta secara sosial dapat diterima oleh masyarakat sekitarnya (Mustafa et al., 2015). Menurut lliyasu (2016) produksi yang rendah hingga kegagalan produksi budidaya tambak di Peninsular Malaysia dapat disebabkan oleh faktor ketidak-efisienan dalam pengelolaan tambak di level petani sehubungan dengan umur, pengalaman budidaya, frekuensi pertemuan dengan penyuluh, tingkat pendidikan, status kepemilikan tambak, ukuran usaha, aksesibilitas ke fasilitas kredit, adaptasi teknologi dan teknik pengelolaan air. Dengan hasil tersebut, lliyasu (2016) menyimpulkan secara umum bahwa pembudidaya yang lebih berpengalaman terutama karena mendapatkan pembinaan yang intensif dari penyuluh perikanan akan jauh lebih efisien dibandingkan dengan yang kurang berpengalaman. Kajian non teknis seperti ini belum banyak dilakukan di Indonesia. Analisis usaha budidaya tambak merupakan gambaran umum kalkulasi secara jelas dari investasi yang diperlukan untuk operasional suatu usaha produksi tambak. Secara garis besar pembudidaya tambak dapat mengetahui penerimaan dan keuntungan yang diperoleh serta berapa lama kemungkinan modal dapat dikembalikan. Telah dilaporkan analisis usaha budidaya udang windu ekstensif di tambak Kabupaten Tanah Bumbu oleh Kisworo (2007) dan udang vaname intensif di tambak Kabupaten Takalar oleh Lawaputri (2011), maka dilakukan penelitian ini yang bertujuan untuk mengetahui analisis usaha berbagai teknologi budidaya tambak di Desa Jayamukti, Kecamatan Blanakan, Kabupaten Subang, Provinsi Jawa Barat.

\section{METODOLOGI}

\section{Waktu dan Lokasi Penelitian}

Penelitian dilakukan pada bulan Februari, Juni, dan September 2014 di tambak yang berlokasi di Desa Jayamukti (Gambar 1), Kecamatan Blanakan, Kabupaten Subang, Provinsi Jawa Barat. Penelitian yang dilakukan pada bulan Februari 2014 dimaksudkan untuk mendapatkan informasi umum budidaya tambak di Kabupaten Subang melalui pertemuan dengan staf Dinas Kelautan dan Perikanan Kabupaten Subang di Subang.

\section{Metode Pengumpulan Data}

Rancangan penelitian ini adalah observasional karena hanya melihat kejadian yang ada di lapangan tanpa melakukan intervensi dari peneliti (Bungin, 2005). Pada bulan Juni 2014 dilakukan pengujian terhadap kuisioner yang telah disiapkan serta menentukan kondisi lokasi tambak yang terpilih yaitu di Desa Jayamukti, mengingat desa tersebut merupakan pusat percontohan silvofishery di Kecamatan Blanakan, Kabupaten Subang. Pengumpulan data dilaksanakan pada pelaksanaan penelitian bulan September 2014. 


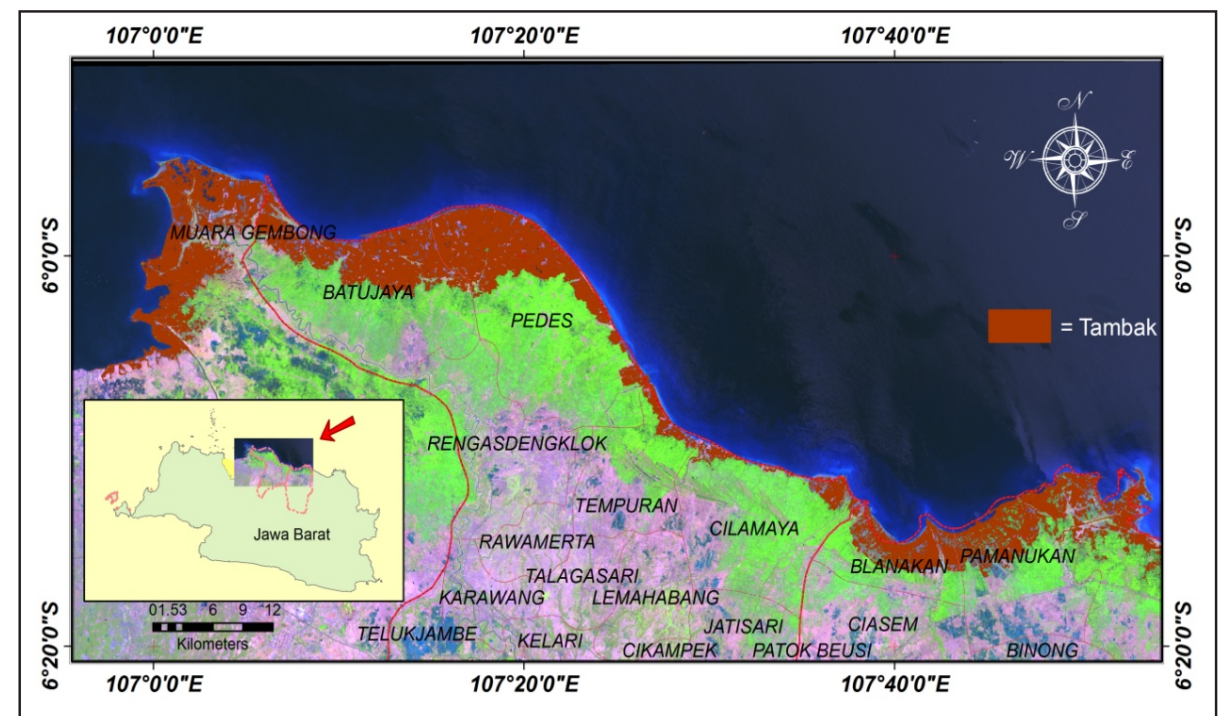

Gambar 1. Lokasi Penelitian di Kawasan Pesisir Kabupaten Subang, Provinsi Jawa Barat.
Figure 1. Study Site in The Coastal Area of Subang Regency, West Java Province.

\section{Jenis dan Sumber Data}

Jenis penelitian yang diaplikasikan adalah studi kasus (case study) yaitu suatu penelitian yang lebih terarah dan terfokus pada sifat tertentu yang tidak berlaku umum sehingga mendapatkan gambaran yang luas dan lengkap dari objek yang diteliti (Daniel, 2002). Responden terpilih berdasarkan pada metode pengambilan contoh dengan sengaja (sampling purposive), dalam hal ini responden terpilih adalah petani ikan yang melakukan budidaya tambak dengan teknologi tertentu dan memiliki luas tambak tertentu pula yang ditetapkan yaitu dengan luas tambak sekitar 1,0 ha untuk teknologi ekstensif dan 0,35 ha untuk teknologi intensif karena besaran luas tambak untuk teknologi intensif relatif lebih kecil dibandingkan teknologi ekstensif dan menurut data besaran rata-rata untuk luasan tambak masingmasing teknologi budidaya di Desa Jayamukti. Jumlah responden sebanyak 40 (empat puluh) yang terpilih dari berbagai teknologi tambak yang ada selama penelitian. Responden terpilih dibagi atas berbagai teknologi budidaya tambak yaitu: monokultur bandeng teknologi ekstensif sebanyak 13 responden (49 tambak), polikultur udang windu dan ikan bandeng teknologi ekstensif 16 responden (22 tambak), polikultur udang vaname dan ikan bandeng teknologi ekstensif 3 responden (7 tambak), dan monokultur udang vaname intensif 8 responden (14 tambak).

Teknik pengumpulan data primer yang diaplikasikan dalam penelitian ini adalah observasi yaitu melakukan pengamatan langsung terhadap kegiatan di lokasi penelitian yang terkait dengan penelitian dan wawancara dengan pengajuan kuisioner (daftar pertanyaan) yang telah disusun secara terstruktur kepada pihak terkait dengan penelitian. Data sekunder diperoleh dari laporan hasil penelitian dan berbagai instansi yang terkait dengan penelitian.

\section{Metode Analisis Data}

Data yang dianalisis diperoleh dari hasil satu siklus budidaya tambak pada tahun terakhir. Jenis analisis yang digunakan dalam analisis usaha dalam penelitian ini adalah:

Biaya total yang digunakan dalam budidaya tambak digunakan rumus (Soekartawi, 1995):

$$
T C=F C+V C
$$

dimana/where:

$T C=$ Biaya total $/$ Total cost

$F C=$ Biaya tetap/ Fixed cost

$V C=$ Biaya tidak tetap $/$ Variable Cost

Penerimaan atau pendapatan kotor diketahui dengan menggunakan rumus:

$$
R=Y \times P S
$$

dimana/where:

$\mathrm{R}$ = Penerimaan/Revenue total

$\mathrm{Y}=$ Produksi yang diperoleh dalam suatu usaha/ Production obtained in a business

PS = Harga jual/Price selling 
Keuntungan operasional dihitung dengan menggunakan rumus:

$$
\mathrm{OPr}=R-V C
$$

dimana/where:

$\mathrm{OPr}=$ Keuntungan operasional/Operating profit

$R=$ Penerimaan/Revenue total

$V C=$ Biaya tidak tetap/Variable cost

Keuntungan bersih dihitung dengan menggunakan rumus (Soekartawi, 1995):

$$
N P r=T R-T C
$$

dimana/where:

$$
\begin{aligned}
& N P r=\text { Keuntungan bersih/Net profit } \\
& R=\text { Penerimaan/Revenue total } \\
& T C=\text { Biaya total/Total cost }
\end{aligned}
$$

Biaya produksi atau harga pokok penjualan dihitung dengan menggunakan rumus:

$$
C P=T C / P d
$$

dimana/where:

$C P=$ Biaya produksi/Cost production

$T C=$ Biaya total $/$ Total cost

$\mathrm{Pd}=$ Produksi $/$ Production

Revenue Cost Ratio (RCRatio) atau rasio penerimaan terhadap biaya total dihitung dengan menggunakan rumus (Hernanto, 1989):

$$
R C \text { ratio }=T R / T C
$$

dimana/where:

$$
\begin{aligned}
\mathrm{RC} \text { ratio }= & \text { Rasio penerimaan terhadap biaya } \\
& \text { total } / \text { Revenue cost ratio } \\
\mathrm{TR} & =\text { Penerimaan total } / \text { Total revenue } \\
\mathrm{TC} & =\text { Biaya total } / \text { Total cost }
\end{aligned}
$$

Break Even Point (titik impas atau titik pulang pokok) dihitung dengan menggunakan rumus:

$$
B E P(\mathrm{Rp})=F C /(1-(C P / P S))
$$

dimana/where:

$$
\begin{aligned}
& B E P(\mathrm{Rp}) \text { = Titik impas dalam rupiah/Break even } \\
& \text { point } \\
& \text { FC= Biaya tetap/Fixed cost } \\
& \mathrm{CP}=\text { Biaya produksi setiap kilogram/ Cost } \\
& \text { Production } \\
& \text { PS = Harga jual setiap kilogram/Price } \\
& \text { Selling }
\end{aligned}
$$

$$
\operatorname{BEP}(\mathrm{kg})=(F C /(P S-C P))
$$

dimana/where:

$$
\begin{aligned}
B E P(\mathrm{~kg})= & \text { Titik impas dalam kilogram/Break } \\
& \text { even point } \\
= & \text { Biaya tetap/Fixed cost } \\
\text { FC } & \text { Harga jual setiap kilogram/Price } \\
& \text { selling } \\
= & \text { Biaya produksi setiap kilogram/Cost } \\
& \text { production }
\end{aligned}
$$

Masa pengembalian modal dihitung dengan menggunakan rumus:

$$
P P(\text { siklus })=I C / N P r
$$

dimana/where:

$$
\begin{aligned}
P P(\text { siklus })= & \text { Masa pengembalian modal dalam } \\
& \text { siklus } / \text { Payback Period } \\
I C & =\text { Biaya investasi/Investment cost } \\
N P r & =\text { Keuntungan bersih/Net profit }
\end{aligned}
$$

$$
P P(\text { tahun })=P P(\text { siklus })
$$

dimana/where:

$$
\begin{aligned}
P P(\text { tahun })= & \text { Masa pengembalian modal dalam } \\
& \text { tahun/Payback period } \\
\text { PP }(\text { siklus })= & \text { Masa pengembalian modal dalam } \\
& \text { siklus/Payback Period }) \\
\text { NC } \quad & \text { Jumlah siklus dalam setahun/ } \\
& \text { Number of cycles }
\end{aligned}
$$

Selanjutnya data di input dan diolah menggunakan Microsoft Excel.

\section{Payback Period (PP)}

Payback Period (PP) digunakan dengan tujuan untuk menghitung jangka waktu pengembalian modal investasi yang digunakan untuk membiayai bisnis. Payback Period adalah suatu periode yang menunjukan berapa lama modal yang ditanamkan dalam bisnis tersebut dapat dikembalikan.

\section{Anilisis Laba Rugi}

Analisis Laba Rugi adalah laporan yang berisi tentang penerimaan pengeluaran dan kondisi keuntungan yang diperoleh suatu perusahaan dalam satu tahun produksi. Laporan laba rugi menggambarkan kinerja perusahaan dalam upaya mencapai tujuannya selama periode tertentu. Laporan laba rugi mengandung sebuah informasi yang penting tentang suatu usaha, yaitu laba atau rugi bersih. 


\section{HASIL DAN PEMBAHASAN}

\section{Profil Budidaya Bandeng dan Udang}

Luas hamparan tambak di Desa Jayamukti adalah 900 hektar (ha), berdasarkan peta petakan tambak dari hasil vektorisasi citra world view-2 diketahui bahwa total luasan hamparan tambak tersebut terdiri atas sekitar 1.370 unit atau petakan tambak. Status kepemilikan sebagian besar (700 ha) adalah milik Perhutani, dan sebagian kecil (200 ha) adalah tanah milik masyarakat. Bentuk petakan tambak tradisional merupakan tipe satu tahapan yaitu hanya berupa petakan pembesaran, dengan luas petakan 0,5-8 ha; dengan luas kepemilikan dominan adalah 2 ha. Jaringan saluran tambak terdiri atas sejumlah saluransaluran membujur yang berhubungan dengan laut (selanjutnya disebut sebagai saluran laut) dan saluran-saluran melintang yang berhubungan dengan kedua buah sungai di sebelah barat dan timur areal pertambakan. Di antara saluransaluran tersebut terhampar blok-blok tambak yang cukup rapi, dengan bentuk petakan tambak persegi panjang. Usaha tambak di Kecamatan Blanakan Kabupaten Subang merupakan aktivitas turun temurun (tradisi) sehingga sebagian besar masyarakat Kecamatan Blanakan berprofesi sebagai petambak. Pengembangan produktifitas tambak di Kecamatan Blanakan Kabupaten
Subang sangat dipengaruhi oleh teknologi. Pendekatan dan pemanfaatan teknologi diyakini menjadi sumber pertumbuhan ekonomi berkesinambungan dalam jangka panjang karena kedua unsur tersebut saling memiliki keterkaitan (Aminullah, 2004).

\section{Prospek Budidaya Tambak}

Kabupaten Subang merupakan salah satu kabupaten dari enam kabupaten di wilayah pantura (Pantai Utara) Pulau Jawa, yang menjadi target program revitalisasi tambak tahap pertama KKP. Dari total 1.000 ha lahan yang diperuntukkan untuk tahap awal revitalisasi tambak, di pantura Jawa Barat, sekitar $45 \%$ atau seluas 360 ha berlokasi di Kabupaten Subang. Komoditas utama yang menjadi andalan adalah udang windu (Penaeus monodon) dan bandeng (Chanos chanos). Pemilihan lokasi revitalisasi tambak didasari oleh potensi utama wilayah tersebut untuk menggenjot kapasitas produksi udang nasional sekaligus sebagai entry point dalam percepatan pembangunan industrialisasi perikanan budidaya di Indonesia (Antara, 2012). Program revitalisasi di Pantai Utara Jawa antara lain difokuskan pada perbaikan infrastruktur melalui efisiensi dan efektivitas rekayasa tambak dan perbaikan cara pengelolaan tambak berdasarkan karakteristik lingkungan. Budidaya yang paling

Tabel 1. Rata-rata Analisis Finansial Usaha Budidaya Ikan di Tambak, Kabupaten Subang, Provinsi Jawa Barat (Permusim Tanam), 2014.

Table 1. Average Financial Analysis of Brackishwater Fish Culture in Subang Regency of West Java Province (Every Culture Cycle), 2014.

\begin{tabular}{lrrrr}
\hline \multicolumn{1}{c}{ Uraian/Description } & TP BW & TP BV & \multicolumn{1}{c}{ TM B } & \multicolumn{1}{c}{ I V } \\
\hline Biaya tetap/ FixedCost (Rp) & $2,725,534$ & $2,020,138$ & $1,570,982$ & $43,768,101$ \\
Biaya operasional/ Operational Cost (Rp) & $4,818,109$ & $3,686,166$ & $1,414,471$ & $256,194,250$ \\
Biaya total/ Total Cost (Rp) & $7,543,644$ & $5,706,305$ & $2,985,454$ & $299,962,351$ \\
Penerimaan I/ Reception I & $7,665,562$ & $3,941,666$ & $6,483,461$ & $535,562,500$ \\
Penerimaan II/ Reception II & $4,783,750$ & $8,166,666$ & - & - \\
Keuntungan operasional/ Operational Profit (Rp) & $7,631,203$ & $4,480,500$ & $5,068,990$ & $279,368,250$ \\
Keuntungan bersih/ Net Profit (Rp) & $4,905,668$ & $3,027,027$ & $3,498,007$ & $235,600,148$ \\
Biaya produksi I/ Production Cost I (Rp/kg) & 11,467 & 27,450 & 7,717 & 27,719 \\
Biaya produksi II/ Production Cost II (Rp/kg) & 54,408 & 73,696 & - & - \\
R/C ratio & 1.75 & 1.41 & 2.33 & 1.88 \\
BEP (Rp) & $25,083,194$ & $19,149,182$ & $3,193,965$ & $120,314,873$ \\
BEP (kg) & 100 & 67.06 & 196.84 & $1,891.01$ \\
Paybackperiod (musim/ season) & 5.42 & 3.92 & 7.91 & 2.47 \\
Paybackperiod (tahun/ year) & 1.81 & 1.31 & 2.64 & 1.23 \\
\hline
\end{tabular}

Keterangan/ Remarks :

TP BW = Tradisional Polikultur Bandeng Windu/ Traditional polyculture of milkfish and penaed.

TP BV = Tradisional Polikultur Bandeng Vaname/ Traditional polyculture of Milkfish and vannamei.

TMB = Tradisional Monokultur Bandeng/ Traditional monoculture of milkfish.

IV = Intensif Vaname/ Intensif culture of vannamei. 
dominan dilakukan di daerah Blanakan adalah usaha budidaya tambak dengan sistem sylvofishery pola empang parit. Kecamatan Blanakan Kabupaten Subang ditunjuk menjadi kawasan minapolitan dengan potensi unggulannya udang vaname. Dalam upaya meningkatkan penghasilan dan hasil produksi usaha masyarakatnya, Direktorat Jenderal Budidaya Perikanan Kementerian Kelautan dan Perikanan, menggandeng beberapa kementerian. Dari hal tersebut dapat terlihat bahwa prospek budidaya tambak di Kecamatan Blanakan sangat potensial untuk dikembangkan.

\section{Analisis Finansial Usaha Budidaya Ikan di Tambak}

Ada beberapa metode penilaian investasi yang bertujuan untuk mengetahui apakah usaha tersebut dapat dikatakan layak usaha atau tidak untuk dilanjutkan/diteruskan. Karena dalam analisis finansial usaha ini akan diketahui keadaan yang mencerminkan perkembangan usaha, terutama untuk masa jangka panjang, terlihat adanya perkembangan finansialnya. Analisis finansial bertujuan untuk mengetahui perkiraan dalam hal pendanaan dan aliran kas, sehingga dapat diketahui layak atau tidaknya bisnis yang dijalankan.

Dari Tabel 1, dapat diketahui perbedaan tingkat kelayakan usaha dari keempat jenis usaha yang dilakukan di Kabupaten Subang Provinsi Jawa Barat. Nilai RC-ratio dapat dilihat dari keempat usaha yang dilakukan. RC-ratio merupakan nilai yang digunakan untuk menentukan tingkat kelayakan suatu usaha merupakan nisbah total revenue dengan total biaya (Pasaribu et al., 2005), dengan kriteria: RC-ratio > 1 menunjukkan budidaya layak dikembangkan, RC-ratio $<1$ menunjukkan budidaya tidak layak dikembangkan dan $R C$ ratio $=1$ menunjukkan budidaya impas. Dari kriteria tersebut nilai $R C$ ratio keempat usaha tersebut > 1 menunjukkan bahwa budidaya layak dikembangkan. Dengan urutan nilai RC-ratio sebagai berikut: TMB 2.33, IV 1.88, TP BW 1.75 dan TP BV 1.41.

Teknologi Monokultur bandeng memiliki nilai RC-ratio tertinggi sebesar 2,33. Hal ini menunjukkan bahwa budidaya monokultur bandeng sangat menguntungkan, sistem monokultur yaitu sistem pemeliharaan dengancara menebar satu jenis komoditas, monokultur memiliki keuntungan yang tinggi, karena lebih mudah dalam hal penanganan, penanggulangan penyakit, pengelolaan air, pemberian pakan dan tidak adanya persaingan di dalam tambak dalam hal perebutan pakan dan ruang. Dari hal tersebut biaya penanganan dan pemeliharaan lebih sedikit sehingga keuntungan yang didapat lebih besar, selama dalam pengelolaan dapat dilakukan dengan baik. Demikian halnya yang terjadi di lokasi penelitian, dari data responden didapatkan informasi bahwa teknologi dengan monokultur bandeng lebih menguntungkan jika dibandingkan dengan teknologi budidaya lainnya disebabkan karena waktu dan biaya yang dikeluarkan selama pemeliharaan hingga panen lebih sedikit, selain itu mudah dalam hal penanganan dan pemeliharaan karena komoditas bandeng tidak mudah terserang penyakit.

Budidaya udang vaname memiliki nilai RC-ratio 1.88, yang diketahui bahwa meskipun pola usahanya intensif dengan membutuhkan modal yang cukup besar tetapi dapat menghasilkan produksi yang tinggi, karena padat tebarnya tinggi, dasar tambaknya menggunakan mulsa atau semen dengan luas petakan tambak dan ketinggian air tertentu, pengaturan air dengan pintu pemasukan dan pembuangan terpisah serta dilengkapi dengan alat pembuangan limbah pakan dan kotoran udang di dasar bagian tengah tambak sehingga risiko terkena penyakit mudah diatasi, pemberian pakan secara otomatis dengan frekuensi pemberian pakan dan dosis pakan secara terprogram, dilengkapi dengan aerasi, maka produksi yang dihasilkan relatif tinggi dengan konversi rasio pakan relatif rendah.

\section{Struktur Biaya dan Pendapatan Usaha}

Selama penelitian berlangsung, tambak teknologi intensif yang ada rata-rata memiliki struktur biaya dan pendapatan usaha yang hampir sama dengan teknologi supra intensif. Menurut Atjo (2013), budidaya udang vaname secara supra intensif menggunakan dasar tambak dari semen, luas petakan tambak $1.000 \mathrm{~m}^{2}$, padat tebar 1.000 ekor $/ \mathrm{m}^{2}$ atau ditebar sebanyak 1 juta benur/petak, kedalaman tambak 3 meter dan saat pemeliharaan ketinggian air sekitar 2,7 meter, dilengkapi dengan aerasi berupa kincir air, turbojet, dan blower, pemberian pakan secara otomatis (automatic feeder) dan alat pembuangan limbah pakan dan kotoran udang di dasar bagian tengah tambak (central drain) yang dioperasikan setiap 6 jam, mampu berproduksi sebanyak 15 ton/petak/siklus dengan rasio konversi pakan 
1,34 dan proses pemanenannya dilakukan secara parsial empat hingga lima kali. Panen pertama saat udang mencapai ukuran 120 (120 ekor/kg) atau size 120. Kemudian dilakukan panen ke dua saat udang mencapai size 100. Pada saat udang sudah mencapai size 70-75 dilakukan panen parsial ketiga. Panen selanjutnya size 55-60 yang biasanya untuk pabrik olahan yang diekspor. Terakhir panen size 40-45. Udang ukuran 70 ekor/kg (size 70) sampai ukuran 50 ekor/kg (size 50), harganya mencapai Rp. 90.000,- sampai Rp. 105.000,-/kg.

Selanjutnya menurut Atjo (2013) menyatakan bahwa analisis usaha untuk budidaya udang vaname secara supraintensif skala $2.000 \mathrm{~m}^{2}$ dengan rincian biaya investasi yang terdiri atas tanah $2.000 \mathrm{~m}^{2}$, konstruksi, peralatan, mesin, dan listrik sebesar Rp 500.000.000,-; modal kerja terdiri atas benih 720.000 ekor, pakan 18.000 kg, sarana produksi lainnya, dan biaya operasional lainnya sebesar $\operatorname{Rp} 317.320 .000,-$, sedangkan nilai produksi dari hasil penjualan udang terdiri atas parsial I (size 86 ekor $/ \mathrm{kg}$ ) $2.600 \mathrm{~kg}=$ Rp 91.000.000,-; parsial II (size 76 ekor/kg) 2.600 $\mathrm{kg}=\mathrm{Rp}$ 106.600.000,-; parsial III (size 66 ekor/kg) $2.700 \mathrm{~kg}=\mathrm{Rp} 124.200 .000$,- dan parsial IV (size 45 ekor/kg) $7.400 \mathrm{~kg}=\mathrm{Rp} 384.800 .000$,- dengan total Rp 706.600.000,-. Biaya produksi per kg udang Rp 20.740,-. Pendapatan kotor Rp 706.600.000,Rp 317.320.000,- = Rp 388.680.000,-. Teknologi tambak intensif vaname hampir sama (identik) dengan yang dikemukakan di atas, perbedaan hanya pada penggunaan plastik mulsa untuk konstruksi tambak sehingga menjadikan tambak yang ada di lokasi penelitian berbeda dengan daerah lainnya.

\section{Analisis Usaha dan Sensitivitas}

Teknologi polikultur bandeng dan windu dengan nilai 1.75 dan teknologi polikultur bandeng vaname memiliki nilai 1.41 merupakan teknologi budidaya yang nilai $R C$-ratio ketiga dan keempat dari keempat teknologi budidaya yang dilakukan oleh pembudidaya tambak di Kabupaten Subang. Nilai TP BW lebih tinggi daripada TP BV hal tersebut dapat dijelaskan bahwa budidaya polikultur merupakan teknik budidaya yang dapat menguntungkan petambak karena dapat memperoleh hasil panen dua komoditas sekaligus dalam satu siklus budidaya, tak hanya untung secara ekonomis, dari segi teknis pemeliharaan juga lebih mudah dan murah. Gerakan ikan bandeng dapat menciptakan riak air yang dapat berfungsi sebagai kincir alternatif untuk pemasok oksigen terlarut maupun untuk menghindari terjadinya stratifikasi (pelapisan) suhu dalam air, secara biologis persyaratan parameter kualitas air untuk kehidupan udang dengan bandeng sama, keduanya tidak akan saling memakan, karena udang windu hidupnya didasar sedangkan bandeng di permukaan. Udang vaname ukurannya lebih kecil dari udang windu, namun udang vaname yang paling banyak diproduksi saat ini. Namun dari segi harga udang windu lebih tinggi dibandingkan dengan udang vaname. Sehingga dari segi finansial polikultur bandeng dan windu lebih menguntungkan apabila dalam proses pemeliharaan dapat dilakukan dengan baik.

Menurut Mangampa et al. (2013), analisis finansial polikultur udang windu, bandeng, dan nila merah di tambak tanah sulfat masam (lahan marginal) yang memerlukan total biaya produksi per musim tanam sebesar Rp 19.000.000,- terdiri atas sewa 1 unit tambak/hektar/tahun sebesar Rp 2.500.000,-; total biaya operasional sebesar Rp 13.380.000,-; penyusutan investasi (sewa 2 unit tambak/musim) sebesar Rp 1.250.000,dan biaya lainnya upah penggarap dan upah panen $(20 \%$ total penjualan)/musim sebesar Rp 4.370.000,-. Hasil penjualan udang sebanyak 235 kg/musim @Rp 60.000,-/kg dengan total harga Rp 14.100.000,-; bandeng 236 kg/musim @Rp 15.000,- total harga Rp 3.540.000,- dan nila merah 240 kg/musim @ Rp 17.500,- total harga Rp 4.200.000,- jadi total penjualan sebesar Rp 21.840.000,-, sehingga keuntungan yang didapatkan per hektar per musim tanam sebesar Rp 2.840.000,- atau per hektar/tahunnya sebesar Rp 5.680.000,-

\section{KESIMPULAN DAN IMPLIKASI KEBIJAKAN}

Berdasarkan hasil penelitian yang telah dilakukan di tambak Kecamatan Blanakan, dengan kondisi luas tambak dan sistem budidaya yang dilakukan, sangat memungkinkan untuk dilakukan pengembangan dan peningkatan usaha budidaya tambak. Dari hasil perhitungan profitabilitas usaha dari nilai RC-ratio yang didapatkan, budidaya secara monokultur bandeng menunjukkan nilai $R C$-ratio tertinggi sebesar 2.33, intensif vaname 1.88, polikultur bandeng windu 1.75 dan polikultur bandeng vaname 1.41. Hal tersebut menunjukkan bahwa dengan kondisi yang ada pada saat penelitian berlangsung masih menguntungkan budidaya monokultur bandeng dibandingkan dengan ketiga teknologi budidaya lainnya. Usaha budidaya tambak udang vaname secara intensif dengan 
teknologi penggunaan mulsa dapat digunakan untuk mendapatkan keuntungan yang tinggi dan berdasarkan tata laksana atau operasional prosedur yang sudah ada.

Saran yang dapat dilakukan oleh petambak agar tetap melakukan kegiatan monokultur bandeng dan dalam mendukung kebijakan serta strategi keberlanjutan pola pengembangan dengan memperluas lahan pembudidayaan, menggunakan benih unggul dan teknik budidaya yang lebih baik. Selain itu, pelatihan-pelatihan bagi para petani usaha tambak yang berbasis teknologi dan penanganan hama agar dapat diterapkan dalam mengembangkan usaha tambak.

\section{UCAPAN TERIMA KASIH}

Terima kasih diucapkan kepada Bapak Utojo yang banyak membantu dalam wawancara langsung di lapangan, Ibu Kamariah, Bapak Rezki Antoni, Bapak M. Arnold, Bapak Darsono dan Maryam atas bantuannya selama penelitian berlangsung.

\section{DAFTAR PUSTAKA}

Aminullah, E. 2004. Berpikir Sistemik. PPM (Id). Jakarta.

Antara. 2012. "Program revitalisasi tambak udang dan bandeng dimulai."Diakses, 2 November 2017 dari http://www.antarasumsel.com/print/268385/ program-revitalisasi-tambak-udang-dan-bandengdimulai.

Atjo, H. 2013. Inovasi budidaya udang.Lebih efisien dengan supraintensif.Sistem supraintensif mampu mengatrol produksi udang. Surat kabar Agrina (Inspirasi Agribisnis Indonesia) "Bisnis Udang Inovasi Baru Pemicu Produksi". Tabloid Dwi Mingguan Vol. 9, No. 212, 8 Oktober 2013, Jakarta, $27 \mathrm{hlm}$.

Bungin, B. 2005. Metodologi Penelitian Kuantitatif Komunikasi, Ekonomi, dan Kebijakan Publik serta IImu-IImu Sosial Lainnya, Edisi Pertama, Cetakan Pertama, Prenada Media, Jakarta.

Daniel, M. 2002. Pengantar Ekonomi Pertanian. Bumi Aksara, Jakarta.

Hernanto, F. 1989. Ilmu Usahatani. Penebar Swadaya. Jakarta.

Husnan, S. M. 2000. Studi Kelayakan Proyek. Yogyakarta: UUP STIM YKPN.

Iliyasu, A., Z. A. Mohamed dan R. Terano. 2016. Comparative analysis of technical efficiency for different production culture systems and species of freshwater aquaculture in PeninsularMalaysia. Journal Aquaculture Reports. Vol (3) : 51-57.
Kadariah, K. L. dan C. Gray. 1986. Pengantar Evaluasi Proyek Edisi Revisi. Jakarta: Universitas Indonesia Press. Sutomo dan Komet Mangiri, Jakarta: Penerbit Universitas Indonesia Press.

Kisworo, Y. 2007. Analisis Usaha Budidaya Tambak Udang dengan Pendekatan Tata Ruang Wilayah pada Kawasan Pengembangan Ekonomi Terpadu Batulicin di Kabupaten Tanah Bumbu Propinsi Kalimantan Selatan. Tesis. Program Pascasarjana, Universitas Diponegoro, Semarang. $92 \mathrm{hlm}$.

Lawaputri, A.T. 2011. Analisis Kelayakan Finansial Usaha Budidaya Udang Vannamei (Litopenaeus vannamei) pada Tambak Intensif di Kabupaten Takalar (Studi Kasus Usaha Tambak Udang Kurnia Subur).Skripsi.Fakultas IImu Kelautan dan Perikanan, Universitas Hasanuddin, Makassar.27 hlm.

Mangampa, M., E. Susianingsih dan B. Pantjara. 2013. Petunjuk Teknis Polikultur Udang windu, Bandeng, Nila dan Rumput Laut di Tambak. Dalam Rachmansyah dan Mustafa, A. (eds.). Badan Litbang Perikanan, Puslitbang Perikanan Budidaya, Balitbang Budidaya Air Payau, Maros, $33 \mathrm{hlm}$.

Mustafa, A., M. Mangampa dan E. Ratnawati.2015. Panen Untung dari Produksi Tokolan Udang dalam Waktu Singkat. Lily Publisher. Yogyakarta.178 hlm.

Pasaribu. A. M., D. Yusuf dan Amiluddin, 2005. Perencanaan dan Evaluasi Proyek Perikanan. LEPHAS. Hasanuddin Universitas Press. Makassar.

Primavera, J. H. 1997. Socio-Economic Impacts of Shrimp Culture. Aquaculture Research.Vol (28): 815-827.

Sapto, A. 2011. Analisa Usaha Perikanan Budidaya. Direktorat Jendral Perikanan Budidaya Balai Besar Pengembangan Budidaya Air Payau Jepara.

Soekartawi. 1995. Analisis Usahatani. Universitas Indonesia Press. Jakarta.

Taofiqurohman, A. dan M. F. A. Ismail. 2012. Analisis spasial perubahan garis pantai di pesisir Kabupaten Subang Jawa Barat. Jurnal IImu dan Teknologi Kelautan Tropis 4(2): 280-289.

Umar, H. 2001. Studi Kelayakan Bisnis Edisi 3 Revisi. Gramedia Pustaka Utama.Jakarta.

Utojo, A. Tompo dan R. A. Suhaimi. 2014.Kesesuaian Lahan dan Revitalisasi Tambak Budidaya Udang di Kawasan Industrialisasi Kabupaten Probolinggo Provinsi Jawa Timur. Jurnal Riset Akuakultur, Desember 2014.Pusat Penelitian dan Pengembangan Perikanan Budidaya, Badan Penelitian dan Pengembangan Kelautan dan Perikanan, Jakarta 3(9): 501-513. 